УДК 316.443

$10.17213 / 2075-2067-2020-6-89-95$

\title{
ПРОФЕССИОНАЛЬНАЯ ДИНАСТИЙНОСТЬ КАК СТРАТЕГИЯ ВОСПРОИЗВОДСТВА МЕДИЦИНСКОЙ ПРОФЕССИИ ${ }^{1}$
}

\author{
(C) 2020 г. О. А. Нор-Аревян, А. И. Черевкова
}

Южный федеральный университет, г. Ростов-на-Дону, Россия

Цель исследования состоит в выявлении стратегий профессионального воспроизводства в медииинских династиях.

Методологическую базу исследования составляет теория соииального воспроизводства П. Бурдье, в рамках которой были выделень 5 классов стратегий воспроизводства.

Эмпирической базой работы выступают проведенные в 2020 2. 20 автобиографических нарративных интервью с представителями медицинских династий, насчитывающих не менее 3 поколений.

Результаты исследования. Наиболее ярко в медицинских династиях выражены проецируемые через одно поколение стратегии наследования, образовательные стратегии, направленные на, как минимум, сохранение достигнутого уровня образования у следующего поколения, а также стратегии символического инвестирования, связанные с поддержанием репутации семьи и имиджа в профессиональном сообществе.

Перспективу исследования составляет дальнейший социологический анализ конструктивного и деструктивного потенциала профессиональных династий в российском обществе, выявление гендерной и межпоколенческой специифики.

Ключевые слова: профессиональная династийность; медицинские династии; теория социального воспроизводства П. Бурдье; образовательные стратегии; стратегии экономических инвестиций; стратегии символического инвестирования.

\section{PROFESSIONAL DYNASTIES AS A STRATEGY FOR REPRODUCING THE MEDICAL PROFESSION}

\author{
(C) 2020 O. A. Nor-Arevyan, A. I. Cherevkova
}

\section{Southern Federal University, Rostov-on-Don, Russia}

The purpose of the study is to identify strategies for professional reproduction in medical dynasties.

The methodological basis of the research is the theory of social reproduction by P. Bourdieu, in which 5 classes of reproduction strategies were identified.

The empirical basis of the work is 20 autobiographical narrative interviews conducted in 2020 with representatives of medical dynasties, numbering at least 3 generations.

The results of the study. Analysis of the interviews showed that the most vividly expressed in medical dynasties are inheritance strategies (projected, as a rule, after one generation), educational strategies aimed at at least preserving the achieved level of education in the next

1 Статья подготовлена при поддержке РНФ проект №19-18-00320 «Конструктивный и деструктивный потенциал профессиональных династий в российском обществе». 
generation, as well as symbolic investment strategies related to maintaining family reputation and image in the professional community.

The prospect of the study. Further sociological analysis of the constructive and destructive potential of professional dynasties in Russian society, as well as identification of gender and intergenerational specifics, is the perspective for the research.

Key words: professional dynasties; medical dynasties; P. Bourdieu's theory of social reproduction; educational strategies; economic investment strategies; symbolic investment strategies.

Введение. В России и в мире медицина как сфера трудовой деятельности традиционно характеризуется высокой долей профессиональных династий в кадровой структуре. Первоначально медицинские династии складывались как агенты трансляции профессионального капитала: в Древней Греции и Риме наряду с храмовой медициной были распространены семейные школы [2, 8], которые, будучи хранителями сакральных знаний и методов лечения, выступали основным агентом профессиональной социализации и обеспечивали кадровое воспроизводство профессии.

С появлением специализированных медицинских учебных заведений роль профессиональных династий трансформировалась. С одной стороны, функция трансляции профессиональных знаний отчасти редуцировалась. С другой стороны, династии с течением времени стали каналами социальной мобильности и, по мнению некоторых исследователей, приобрели характер социальных монополий, ограничивающих вхождение в профессию и затрудняющих доступ к высоким профессиональным статусам для нединастийных членов [6].

С этой точки зрения, профессиональная династийность может рассматриваться как стратегия социального воспроизводства, нацеленная на сохранение существующего порядка и социально-профессиональной структуры. Совокупность всех стратегий воспроизводства, понимаемых как набор социальных практик семьи или группы, была разбита П. Бурдье на 5 основных классов, которые «на практике могут зависеть друг от друга и переплетаться»: 1) стратегии биологических инвестиций; 2) стратегии наследования; 3) образовательные стратегии; 4) стратегии экономических инвестиций; 5) стратегии символического инвестирования [1, 7]. Далее на эмпирических материалах рассмотрим проявление перечисленных классов стратегий воспроизводства в профессиональных династиях врачей.

Эмпирической базой работы выступают результаты прикладного исследования, проведенного в 2020 г. в различных городах России (Волгодонск, Москва, Ростов-на-Дону, Саратов, Уфа и др.). В ходе исследования методом автобиографического нарративного интервью было опрошено 20 медиков, которые являются представителями 15 семей, являющихся медицинскими династиями, насчитывающими минимум 3 поколения (в пяти семьях интервью проводились с представителями двух поколений). Информация о стратегиях воспроизводства в профессиональных династиях была получена в ходе начального нарративного рассказа информантов, а также с помощью уточняющих вопросов: Кто занимался Вашим воспитанием? Какое участие принимали родители в вашем образовании? Как происходил выбор Вами профессии? Какие обстоятельства и какие люди на это повлияли? Обсуждали ли Ваши родители и другие свою работу в семейном кругу? Хотели ли бы Вы, чтобы Ваши дети продолжили вашу профессию? и т.п.

Анализ полученной эмпирической базы с позиций теории социального воспроизводства позволил выявить функционирование в династиях нескольких классов стратегий.

Стратегии биологических инвестиций согласно П. Бурдье представляют собой долгосрочные стратегии, влияющие на все будущее потомство и его наследство. Они определяют силы семейной группы, и от количества детей в семье зависит число 
потенциальных претендентов на материальное и символическое наследство [1]. В медицинских семьях точно так же потенциал продолжения династии закрепляется не обязательно за всеми детьми, то есть продолжателем династии может стать, по крайней мере, один потомок, наиболее способный, наиболее увлеченный, сделавший осознанный выбор профессии. В высказываниях информантов были такие сюжеты, когда они говорили о своем выборе профессии, сравнивая себя с братьями/сестрами: «Насколько я себя помню, в семье с детства говорили, что я буду доктором, потому что я любила играть в больничу, всех перевязывала, мазала зеленкой все царапинки всех детей на улице. За мной это дело с детства закрепилось. <...> Но, может быть отрицание, когда ребенок не захочет идти в профессию. Я из своего детства вспоминаю свою старшую сестру, которая была изнеженньлм ребенком, она боялась уколов, крови, со страхом ходила в медииинский кабинет. C детства можно увидеть трудности, радости и прелести» (педиатр, 70 лет, жен., 2-е поколение династии из 3); «Молодое поколение все это видит, впитыввает отношение предыдущчего поколения к профессии. Если оно видит самоотдачу, любовь, стремление, то наверное, это заразительно. Не наверное, а точно... Что касается отрицательных сторон, то в семье не без урода... Примазываюшихся и как-то использующчих свои данные людей тоже, думаю, в каждой династии существует энное количество» (кардиолог, 42 года, жен., 3/3); «Нy, своего медика в семье надо иметь. С дочерью у нас было так - она: "Хочу психология и медицина”. И мы решили так: “Давай ты пойдешь в медучилище, закончишь медучилище и определишься уже - твое, не твое". И она пошла в медучилище и после медучилища уже пошли дальше. Потому что, ладно, если медучилище закончил, по жизни это нужно будет, если даже не будешь медиком, пригодится. Но кончать институт и не работать по специиальности, по профессии, которую получил, - это уже роскошь в наше время была. <..> Когда в семье есть один медик, даже на несколько семей один медик, это уже страховка определенная» (врач, начмед, 64 года, жен., 2/3). В це- лом стратегия биологических инвестиций не просматривается в интервью явно, но информанты утверждают: «... Чтобы быmь хорошим врачом, нужно мозги иметь, нужно интеллект иметь» (оториноларинголог, 61 год, жен., 2/3).

Более явно в проведенных интервью отражено влияние стратегии наследования. Практически каждый информант упоминал о том, как важно, чтобы в семье были последователи. И если сами родители говорили неоднозначно о выборе профессии врача своими детьми, то старшему поколению очень хотелось бы, чтобы внуки стали продолжателями династии: «Мы с супругой никогда не считали, что он доложен стать врачом. Если не хочет, и не нужно. А дедушка его, мой папа, очень болезненно к этому отнесся: династия, сам Бог ему велел, и в медицине мы ему поможем на этапе получения выстего образования, на этапе трудоустройства. А в любой другой сфере мьл ему помочь не сможем» (хирург, зав. отделением, д.м. н., 43 года, 3/4); «Дед очень хотел преемственности поколений, ему очень важно было, чтобы внучка была врачом. Внучка была врачом и носила его фамилию» (психиатр, 37 лет, жен., 3/3); «Иногда в медицинских семьях, наоборот, не хотят, чтобь дети шли по стопам родителей. У нас такого не было, меня все поддержали. Дедушка был очень рад, что я выбрала эту профессию» (врач-кардиолог, 34 года, жен, 4/4).

Образовательные стратегии представляют собой «осознанную рефлексивную модель образовательного поведения, сформированную под влиянием совокупности образовательных, профессиональных и социальных ориентаций» [5]. Это долгосрочные инвестиции, направленные «на производство социальных агентов, достойных и способных наследовать свойства группы» [7]. Получение диплома медицинского вуза является обязательным формальным условием для осуществления врачебной деятельности и допуска в профессиональное сообщество.

Профессиональные династии формируют особую внутрисемейную атмосферу, которая подталкивает детей к решению пойти по стопам родителей: «Mы жили в медицине постоянно, папа был главным врачом, дед тоже, я рос в этом, мы постоянно были среди этого, нас водили в больнииу» (терапевт, 
организатор здравоохранения, муж., 30 лет, 3/3). В результате дети в семьях-династиях к моменту поступления в вуз часто не видят альтернатив: «A куда? Никакой другой сnецииальности мы не знали. И не рассматривалось ничего. Кем можно быть, кроме врача, если мама - врач, папа - врач?» (оториноларинголог, жен., 61 год, 2/3).

В семьях-династиях транслируется установка на обязательное получение детьми высшего образования: «Родители всегда хотели, чтобы образование было высшее, не среднее, всегда к этому меня подталкивали, мотивировали» (врач, жен., 34 года, 3/4). Кроме того, родители ориентируют детей на получение более высоких уровней образования (интернатура, ординатура) и ученых степеней: «Я помню, когда сын получил красный диплом, он спустился с лестницы и говорит: "На! Хотела красный диплом? На - получи!” (смеется в голос). А я говорю: “А можно мне ещце корочку? Диплом к. мед. н., и я отстану”” (оториноларинголог, жен., 59 лет, 2/3).

Выбор того или иного вуза в династиях определяется как общими критериями, такими как территориальная близость, проходной балл ЕГЭ, так и специфическими для династийной среды - репутация учебного заведения в медицинском сообществе, опыт обучения родителей в том или ином вузе, возможность использования семейных социальных связей для помощи в учебе и последующем трудоустройстве: «Была сложная ситуация с тем, прохожу я в Москву или нет, но родители все равно больше хотели, чтобы я поступила в наш мед, потому что, по их мнению, они мне могут, если что, помочь, найти мне работу, если вдруг что. А если я уеду, тем более, в Москву, в другой город, и на направление, с которьм у них нет никаких связей, ничего, это будет сложнее и неприятнее» (студентка медицинского вуза, 18 лет, 3/3).

Стратегии экономических инвестиций направлены на сохранение и увеличение экономического капитала семьи. Экономической инвестицией может выступать и сам выбор профессии, как, например, профессия юриста или экономиста. Однако, в ходе нашего исследования информанты указывали на то, что не считают медицину финансово благоприятной сферой и отчасти по этой причине они не рекомендовали бы своим детям вы- бор этой сферы: «Медициина - это немножко другое. Все равно человек должен быть профессионалом. Сейчас это не очень котируется. Честность сейчас не котируется, порядочность не котируется. < .. > Вот для меня, по крайней мере, это полушоковое состояние - глядеть на сегодняшних врачей, как они берут деньги, хотя операция проводится бесплатно. <...> Ну, время такое наступило. К сожалению. Нет того, что было раньше, когда медик независимо от твоего положения и твоего кошелька занимался пацุиентом» (врач, начмед, 64 года, жен., 2/3); «Hу, вы знаете, я думаю, если бы она не пошла в медицину, она гораздо больиего добилась бы. Ну, просто медицина, она очень... консервативна, в ней нельзя заработать много денег, в ней нельзя добиться славы, ничего, а в других спецчиальностях можно... Медицүина - это не та специиальность, которую надо выбирать для жизни» (оториноларинголог, 61 год, жен., 2/3).

Случается и так, что медицинская профессия приносит огромное удовлетворение, высоко оценивается клиническая работа с пациентами, но чтобы удержаться на плаву и обеспечить финансовое благополучие своей семьи, информантам приходится строить управленческую карьеру или менять направленность своей профессиональной деятельности, переходить на смешанные формы занятости в негосударственный сектор: «Многие, очень многие ушли не в практическую медицину, а в медицину, которая связана с продвижением лекарств, медаппаратуры. Некоторые вообще уили в бизнес, имеют рестораны, магазины, потому что определенныле ситуации есть в медицине, которые не перебьешь» (лор-врач, 59 лет, жен., 2/3); «Врач не может быть самозанятым, потому что это лицензированная деятельность, а психолог может, поэтому у меня практика именно психологическое консультирование. И я остаюсь врачом зиловской больницьь, ношу халат» (врач-психиатр, 37 лет, жен., г. Москва); «Кому-то просто надоедает, и он уходит из профессии. Кто-то где-то начинает тормозить на каком-то этапе. Я бы сказала 50 на 50» (кардиолог, жен., 35 лет, 4/4). При этом в высказываниях информантов прослеживается, что ни управленческая работа, ни коммерческая медицина не приносят 
такого морального удовлетворения и чувства гордости за то, что ты делаешь: «Я немножечко не умею, наверное, быть коммерческим врачом. Я не умею оказывать медицинские услуги. И, соответственно, в коммерческих структурах ты получаешь заработную плату ровно столько, сколько ты сам ее наработал. Ну, то есть ты должен быть нацелен на коммерческий результат. А это достаточно сложно и, может быть, я окажусь не права, но, на мой взгляд, это все-таки иногда идет вразрез с интересами пациенma» (акушер-гинеколог-репродуктолог, жен., 29 лет, 3/3); «Есть у меня коллеги, которые, занимая должность заведующего отделением, стремятся расти по карьерной лестнице, стать замом главврача, главврачом, еще какие-то должности в административном смысле. Я с ужсасом думаю о подобном, чтобы у меня было меньше клинической работы и больше административной. Мне кажется, что ничего хуже в моей жизни произойти не может. ... Если бы не было работы клинической, я бы, наверное, давно выгорел и стал искать что-то другое. Именно возможность оперировать, лечить больных, получать результат, видеть его - это для меня самое ценное, это позволяет продолжать работать здесь и мириться с какими-то вещами, которые мне неприятны, но их надо делать» (хирург, зав. отделением, д.м.н., 43 года, 3/4).

Стратегии символического инвестирования объединяют «все действия, направленные на сохранение и увеличение капитала признания» [1]. Ключевым аспектом в символическом инвестировании выступает сохранение и поддержание положительной репутации семьи, формирование так называемого «фамильного бренда». Говоря о репутации семьи, информанты отмечали, что она «крайне положсительная, т.к. основой является мама. Она всю жизнь работает в медуниверситете. <..> Всегда все восхишаются и на меня, конечно, это проецируют. Безусловно. И мне это очень помогает на начальных этапах, получить какую-то поддержку и доброжелательность» (кардиолог, жен., 34 года, 4/4).

Вместе с тем принадлежность к династии и известная фамилия могут не только облегчать карьерный рост молодого поколения, но и накладывать большую ответственность [4], связанную с сохранением репутации се- мьи и имиджа в профессиональном сообществе: «Когда у тебя до 3-го колена все врачи, это же... врачебный мир, он же не так велик. Все друг друга знают прекрасно. И риск опозориться выше, чем у кого бы то ни было другого. На кого-то и внимания не обратят, а тебя обязательно потом не раз вспомнят» (хирург, муж., 53 года, 2/3).

Важным средством закрепления символического капитала выступают упоминания династии в СМИ, а также участие в различных профессиональных сообществах и конкурсах [3]. Некоторые информанты после интервью с гордостью демонстрировали семейные реликвии - опубликованные в газетах и журналах статьи о вкладе семьи в медицину, фотографии с рабочим коллективом, наградные знаки.

Заключение. Анализ автобиографических нарративных интервью позволяет сделать вывод, что все 5 предложенных П. Бурдье классов стратегий имеют место в профессиональных династиях врачей. Наиболее ярко в медицинских династиях выражены стратегии наследования (проецируемые, как правило, через одно поколение), образовательные стратегии, направленные на, как минимум, сохранение достигнутого уровня образования у следующего поколения, а также стратегии символического инвестирования, связанные с поддержанием репутации семьи и имиджа в профессиональном сообществе.

Профессиональная династийность выступает стратегией воспроизводства медицинской профессии. Это находит отражение в представлении медиков о том, что такое профессиональная династия: «Необходимость поддержки профессии и продолжения ее непосредственно в семье. Именно прививание детям последуюших поколений желания работать в этой профессии» (педиатр, жен., 70 лет, 2/3). В дальнейшем эта любовь к профессии, внутреннее понимание ее особенностей обеспечивают легкое вхождение в профессию и ее естественное воспроизводство в рамках профессиональной династии.

\section{Литература}

1. Бурдье П. Социология социального пространства / Пер. с франц.; отв. ред. пере- 
вода Н.А. Шматко. - М.: Институт экспериментальной социологии; СПб.: Алетейя, 2007. - 288 c.

2. Грицак Е.Н. Популярная история медицины. - Москва: Вече, 2003.

3. Нор-Аревян О. А, Черевкова А.И. Роль СМИ в формировании образа профессиональных династий в сфере здравоохранения// Актуальные вопросы экономики и социологии: сборник статей по материалам XV Ocенней конференции молодых ученых в новосибирском Академгородке / под ред. О.В. Тарасовой, Н.О. Фурсенко - Новосибирск: ИЭОПП СО РАН, 2019. - С. 213-218.

4. Нор-Аревян О.А. Стратегии воспроизводства профессиональной медицинской династии // Гуманитарий Юга России. 2020. - T. 9. — №4 - C. 62-72.

5. Озерова М.В. Образовательные стратегии студентов вузов: подходы к исследованию // Культура, личность, общество в современном мире: методология, опыт эмпирического исследования. (XI Международная конференция, Екатеринбург, 19-20 марта 2008 г.): в 5 частях. - Екатеринбург, 2008. Ч. 3. - C. 159-161.

6. Посухова О.Ю. Профессиональная династия как результат семейных стратегий: инерция или преемственность? // Власть. 2013. — №12. - C. 100-103.

7. Bourdieu P. Stratégies de reproduction et modes de domination, en: Actes de la recherche en sciences sociales. — 1994. — Vol. 105. — Pp. 3-12.

8. Davidson J.R. The Wesselhoefts: Amedical dynasty from the age of Goethe to the era of nuclear medicine. J Med Biogr. — 2017. №25(4). - Pp. 214-222.

\section{Referenses}

1. Burd'e P. Sociologija social'nogo prostranstva [Sotsiologiya sotsialnogo prostranstva]/ In N.A. Shmatko (eds.). - Moscow: Institut jeksperimental'noj sociologii; Saint-Petersburg: Aletejja, 2007. - 288 p.

2. Gricak E.N. Populjarnaja istorija mediciny [Popular history of medicine]. - Moscow: Veche, 2003.
3. Nor-Arevjan O. A, Cherevkova A.I. Rol' SMI $\mathrm{v}$ formirovanii obraza professional'nyh dinastij $\mathrm{v}$ sfere zdravoohranenija [The role of mass media in shaping the image of professional dynasties in the healthcare sector] // Aktual'nye voprosy jekonomiki i sociologii: sbornik statej po materialam XV Osennej konferencii molodyh uchenyh $\mathrm{V}$ novosibirskom Akademgorodke [Topical issues of Economics and sociology: a collection of articles based on the materials of the XV Autumn conference of young scientists in Novosibirsk Akademgorodok] / In O.V. Tarasova, N.O. Fursenko (eds.). Novosibirsk: IJeOPP SO RAN, 2019. Pp. 213-218.

4. Nor-Arevjan O.A. Strategii vosproizvodstva professional'noj medicinskoj dinastii [Strategies of reproduction of professional medical dynasty]// Gumanitarij Juga Rossii [Humanities of the South of Russia]. - 2020. Vol. 9. - №4 - Pp. 62-72.

5. Ozerova $M . V$. Obrazovatel'nye strategii studentov vuzov: podhody $\mathrm{k}$ issledovaniju [Educational strategies of University students: approaches to research] // Kul'tura, lichnost', obshhestvo v sovremennom mire: metodologija, opyt jempiricheskogo issledovanija. (XI Mezhdunarodnaja konferencija, Ekaterinburg, 19-20 marta 2008 g.): v 5 chastjah [Culture, personality, society in the modern world: methodology, experience of empirical research. (XI international conference, Yekaterinburg, March 19-20, 2008): in 5 parts]. — Ekaterinburg, 2008. - Issue. 3. - Pp. 159-161.

6. Posuhova O. Ju. Professional'naja dinastija kak rezul'tat semejnyh strategij: inercija ili preemstvennost'? [Professional dynasty as a result of family strategies: inertia or continuity?]// Vlast' [Power]. — 2013. №12. - Pp. 100-103.

7. Bourdieu P. Stratégies de reproduction et modes de domination, en: Actes de la recherche en sciences sociales. - 1994. — Vol. 105. Pp. 3-12.

8. Davidson J.R. The Wesselhoefts: A medical dynasty from the age of Goethe to the era of nuclear medicine. J Med Biogr. 2017. — №25 (4). — Pp. 214-222. 


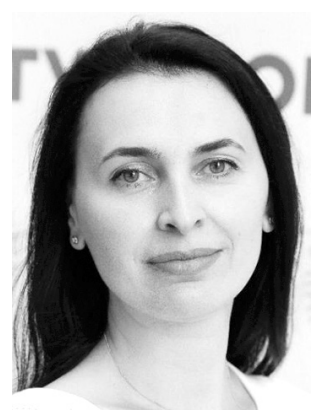

Нор-Аревян Оксана Аведиковна - кандидат социологических наук, доцент, доцент кафедры прикладной конфликтологии и медиации Института социологии и регионоведения Южного федерального университета.

Nor-Arevyan Oksana Avedikovna - Candidate of Sociological Sciences, Associate Professor of the Department of Applied Conflictology and Mediation, Institute of Sociology and Regional Studies, Southern Federal University.

344006, г. Ростов-на-Дону, ул. Пушкинская, 160 160 Pushkinskaya st., 344006, Rostov-on-Don, Russia

E-mail: noroks@yandex.ru

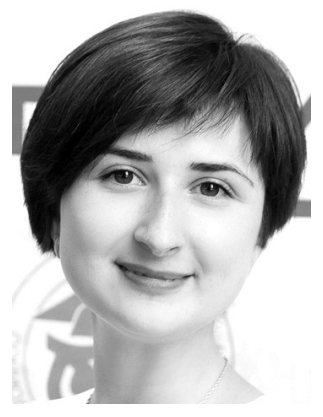

Черевкова Алена Игоревна - аспирант, стажер-исследователь Института социологии и регионоведения Южного федерального университета.

Cherevkova Alena Igorevna - Postgraduate student, Research Assistant, Institute of Sociology and Regional Studies, Southern Federal University.

344006, г. Ростов-на-Дону, ул. Пушкинская, 160 160 Pushkinskaya st., 344006, Rostov-on-Don, Russia

E-mail: yaitskova_a@mail.ru 